\title{
Rationale and Design of EU Cohesion Policies in a Period of Crisis Roberto Camagni ${ }^{1, a}$, Roberta Capello ${ }^{1, b}$ \\ ${ }^{1}$ Politecnico di Milano, Dept. of Architecture, Built environment and Construction engineering \\ aroberto.camagni@polimi.it, broberta.capello@polimi.it
}

Keywords: Territorial Cohesion, Regional Policies, Territorial Capital.

\begin{abstract}
The aim of the paper is to reflect on the justifications and design of cohesion policies in a period of deep economic recession. In particular, the paper tackles two important topics. The first topic deals with the justification for structural policies like cohesion policies in a period of economic downturn, since they look less urgent and appropriate than short term demand policies. In this case, cohesion policies are called to rebalance the effects that the ongoing crisis has on the convergence trends of the last two decades. The second topic relates to the most appropriate design that cohesion policies should have. The message that the paper provides from a conceptual point of view, corroborated by empirical results, is that the winning strategy is neither to focus on champions, calling for competitiveness, nor on lagging areas, in favor of cohesion; policies targeted to each regions' needs are the right policies, able to enlarge and embrace all possible excellences. This strategy demonstrates that the traditional trade-off between efficiency and equity goals may be overcome.
\end{abstract}

\section{Introduction}

The paper addresses some important aspects regarding cohesion policies that became even more stringent in recent years: how can cohesion policies be justified in a period of crisis when shortterm, anti-cyclical policies intended to boost internal demand look more appropriate? Which role remains for cohesion policies when macro-economic policies are put in place to control the critical condition of sovereign deficits and debts? How have cohesion policies to be designed in order to provide the highest returns in terms of both competitiveness and cohesion?

The paper presents a series of reflections in this direction. Especially on the design and implementation of cohesion policies, there has been a renewal of the general strategy linked to the new structural funds period 2014-2020, with new rules and conditionalities mainly linked to the Barca Report [1] and to the Smart Specialization approach [2].

The specific aim of the paper is to add some new elements to this debate, related to the particular period of economic crisis. The crisis, which started mainly in the financial context and then hit the "real" economy, brings financial issues back to the forefront, with the difficulties, costs, and risks taken by sovereign debts on the financial markets. This obviously implies a much more stringent path out of the crisis. Strict macroeconomic policies are imposed to countries, with two direct consequences: public funds allocated to structural, long-term, objectives have to be justified more than before and the assumed traditional trade-off between competitiveness and cohesion goals is strongly back in the policy debate, generally attributing a priority to the competitiveness issue due to the widely felt need for a growth strategy. But a sound supply-side and place-based approach may help overcoming, at least partly, these limitations. 


\section{Main challenges and justification for a renewed regional policy strategy}

Due to the increasing difficulties that territorial approaches towards development encounter nowadays, a theoretical reflection on the economic rationale for a territorial approach to development is in order. This rationale may be found in the following elements:

A - In a context of international integration, especially in the earlier periods, market forces determine concentration of activities and an increase of regional disparities. This is due to the cumulative nature of development processes and to the limited capability of spontaneous adjustment processes to rebalance differentiated regional starting conditions ([3] ch. 4). In periods of crisis, these processes are enhanced by the higher resilience and reaction capability of stronger regions ${ }^{1}$. Are these spontaneous trends an acceptable or a desirable outcome?

B - The absence, in an inter-regional context, of some powerful macroeconomic adjustment mechanisms that work at the level of countries (devaluation of currencies, flexibility of prices and wages) and that are able to guarantee each country a role in the international division of labour, according to the well-known Ricardian principle of comparative advantage. These mechanisms and policy tools are not present at the regional level and, whenever a region presents lower rates of productivity growth with respect to other regions or other structural deficits (e.g. in accessibility), its fate is out-migration and even, at the extreme, 'desertification'. All this can be summarized in the statement that regions compete according to a Smithian principle of 'absolute advantage', not to a Ricardian principle of 'comparative' advantage [4] and confirms that the trend towards increasing disparities inside each country is the most likely outcome.

$\mathrm{C}$ - The evidence of huge economic costs of non-intervention in a context of increasing disparities and globalization provides even clearer support to spatial development policies. A strategy of non intervention in fact presents the following drawbacks ([5] ch. $1 ;[6])$ :

- the risk of a super-concentration of population and jobs in advanced regions and cities, with high risks of inflationary pressures. This happened in many EU countries after joining the Union: Italy in the early 1960's, Spain and Ireland in the 1990's; the New Eastern Member Countries in the 2000's;

- the high opportunity cost of adding new activities in already successful areas;

- the channelling of a wide share of national savings towards the building and construction industry and real estate speculation in advanced regions and cities, as a consequence of the migration processes, subtracting it from more productive uses;

- a lower exploitation of the creativity potential of all regional communities constrained by the presence of some basic locational disadvantages (accessibility, services, infrastructure).

Other justifications can be further proposed in favor of cohesion policies, and they refer to the fact that 'territory matters' in the development process. In fact:

D. Globalisation has taken to the fore the growing importance of spatial proximity, not in the sense of a shelter to the benefit of local markets and communities but in the sense of the growing importance of local conditions for global economic success. Territories not only supply the infrastructure and service preconditions for successful location decisions and the skills and

\footnotetext{
${ }^{1} \mathrm{Up}$ to the beginning of the present crisis, during more than two decades the convergence of regional GDPs in the EU was due to the catching up of weaker countries and not to a reduction of inter-regional disparities inside the single countries. During the crisis a slowing catching up process by the new Eastern member states and the deep crisis of many southern European countries was not in a measure to counterbalance the general increase in within-countries disparities (a it will be shown later).
} 
competencies needed for economic growth, but represent a crucial stock of non-mobile social and 'relational' capital.

E - The increasing importance of knowledge factors, of immaterial elements linked to culture, taste and creativity in present economic processes are deeply embedded into slow learning processes, inherently localised and cumulative, as they are embedded in human capital, interpersonal networks, specialised local labour markets and local innovative milieux [7] [8] ${ }^{2}$.

F - General institutional conditions operating at the national level are crucial. For instance, we can think of factors such as the regulation of the labour market, market transparency and risk control in financial markets, market openness (antitrust practices), fiscal homogeneity (across countries), etc. However, as shown by Armstrong and Taylor [9], spatial characteristics and local and regional institutions also play a major role in speeding up or hindering the economic transformation process.

G - Social and economic cohesion (in other words, 'equity', as it was called in previous decades) represents one of the main political goals of any society and this was authoritatively assumed as one of the founding principles of the European Union. Recently, however, another goal, namely 'efficiency' or aggregate 'competitiveness', has become increasingly prominent [10]. Yet, the relationship between the two goals was never explored in depth: a clear trade-off was often hypothesized but it now requires further reflections.

H. Finally, the restrictions to macroeconomic and fiscal policies imposed to highly indebted countries exert an influence on regional disparities. Macroeconomic trends and policies are likely to generate asymmetric and differentiated regional impacts, especially in periods of financial turmoil and sluggish development, for many reasons. The first, and most straightforward reason lies in the fact that regions belong to different countries, and countries show a diversified resilience to economic downturns because of the different levels of sovereign debt, different public deficits, and therefore different availability of public resources to be devoted to growth policies and regional support. All this is responsible for some strong and well visible 'country effects' in the map of regional performance in Europe after 2007.

The second reason is more subtle and refers to more selective spatial effects. Let us consider the most relevant macroeconomic effect of the financial crisis, namely the widening of the spread - the risk premium requested on public bonds with respect to riskless bonds:

1. a strong control on, and reduction of, public expenditure was imposed by the EU, with stronger likely effects on regions relying more on public demand, being generally the poorer and less productive ones;

2. private investments decreased as a consequence of the increase in interest rates on private loans and bonds, penalizing private actors, and particularly industrial regions with large shares of SMEs;

3. a credit crunch came as a consequence of the financial intermediaries' decision to prefer investing on public bonds rather than on the private sector, when sufficient guarantees existed against possible sovereign default; the real sector and the highly productive but financially fragile SMEs were most strongly hit.

Regional forecasting models, well structured in order to include both regional supply-side assets and national, demand-side macro-economic elements, could assist in disentangling the single

\footnotetext{
${ }^{2}$ We see here a complex dialectics between the hyper-mobility of some production factors and the territorial 'anchorage' of some others, which act as crucial location factors for the more advanced production processes. The likely result is the cumulative strengthening of the centripetal forces of growth (scale and scope economies, all sorts of increasing returns) and the centrifugal forces of territorial exclusion and decline.
} 
different logical chains leading from macro-economic constraints to regional impacts in the recent past, and in building an ex-ante picture of the likely macroeconomic trends out of the present crisis and their regional distribution. A recent simulation exercise was recently carried out in the ESPON ET2050 project, based on a model of this kind, called MASST [11] [12]. The last version of the model, MASST3 [13], warrants particular attention since it is particularly apt: i) to measure the costs of austerity and growth measures, and their interactions and feedbacks, both in periods of crisis and of economic expansion; ii) to interpret the heterogeneous regional effects that the economic downturn and the subsequent expected recovery are likely to generate.

The results of the 'Baseline' scenario are presented in Fig. 1 in terms of annual average regional GDP growth rate in the 2012-2030 period. They show that GDP growth will be positive in all European regions, with the exception of a very limited number of regions in southern Europe. Moreover, in terms of GDP growth rate, a two-speed Europe appears, since regions belonging to southern countries grow in general significantly less than northern countries. Finally, the convergence process by New12 countries remains incomplete: Eastern European countries still grow more than the others, but not enough to catch up with the GDP per capita levels of the Western countries by 2030 .

Looking at the spatial imbalances caused by the crisis, it appears that the lack of adequate development policies risks to jeopardize two decades of efforts towards EU enlargement and cohesion. By looking at between-countries disparities in GDP (Fig. 2), where the values of the Theil index are plotted for the period 1995-2012 on official statistics and then up to 2030 on modelling forecasts, it appears quite evidently that the long-run convergence process was interrupted during the crisis and that it is likely to slow down substantially now on. Its sluggish pace will be insufficient to counterbalance the forecasted increase in inside-countries disparities (that was also observed in past decades), so that the index of overall regional disparities is expected to increase from now to 2030 .

\section{Competitiveness vs. cohesion: a traditional and possibly outdated trade-off}

If regional policy finds a strong rationale and justification not just on equity grounds, as it was shown in the previous section, its relation and widely assumed opposition to economic development policy should be carefully revisited. A strategy favoring the highest returns on investments on core and 'champion' areas, in order to achieve the highest aggregate growth rates and obtain highest fiscal revenues on which redistributive policies can rely, has often been conceptualized as the most appropriate, especially in periods of general crisis [10] [14]. The opposed strategy, oriented towards support to lagging regions, was traditionally advocated mainly for social equity and cohesion goals, but more recently also on the ground of its contribution to growth, when competitiveness of these regions is taken up as its main target [15] [16] [19] [1].

That modern spatial development policies should be designed so as to maximize the collective returns to public investments is a right and shared idea. However, this goal is not necessarily reached through investments in strong areas, but through the capability of single policies to mobilize and "tap" previously "untapped" assets of territorial capital, and use them in the most efficient ways. The aggregate development effects will be in this way maximized, and at the same time the economic and social costs of an unbalanced development process kept under control.

As the Community Strategic Guidelines for Cohesion Policy have rightly and trail-blazing pointed out [15], the preconditions for development widely lie in a hugely differentiated and scattered endowment of "territorial capital", made up of natural and artificial specificities, varied settlement structures, cognitive and relational assets at different degrees of complexity and 
development. All these elements - especially those that are not yet fully or creatively exploited represent the assets and potentials on which any development strategy should rely.

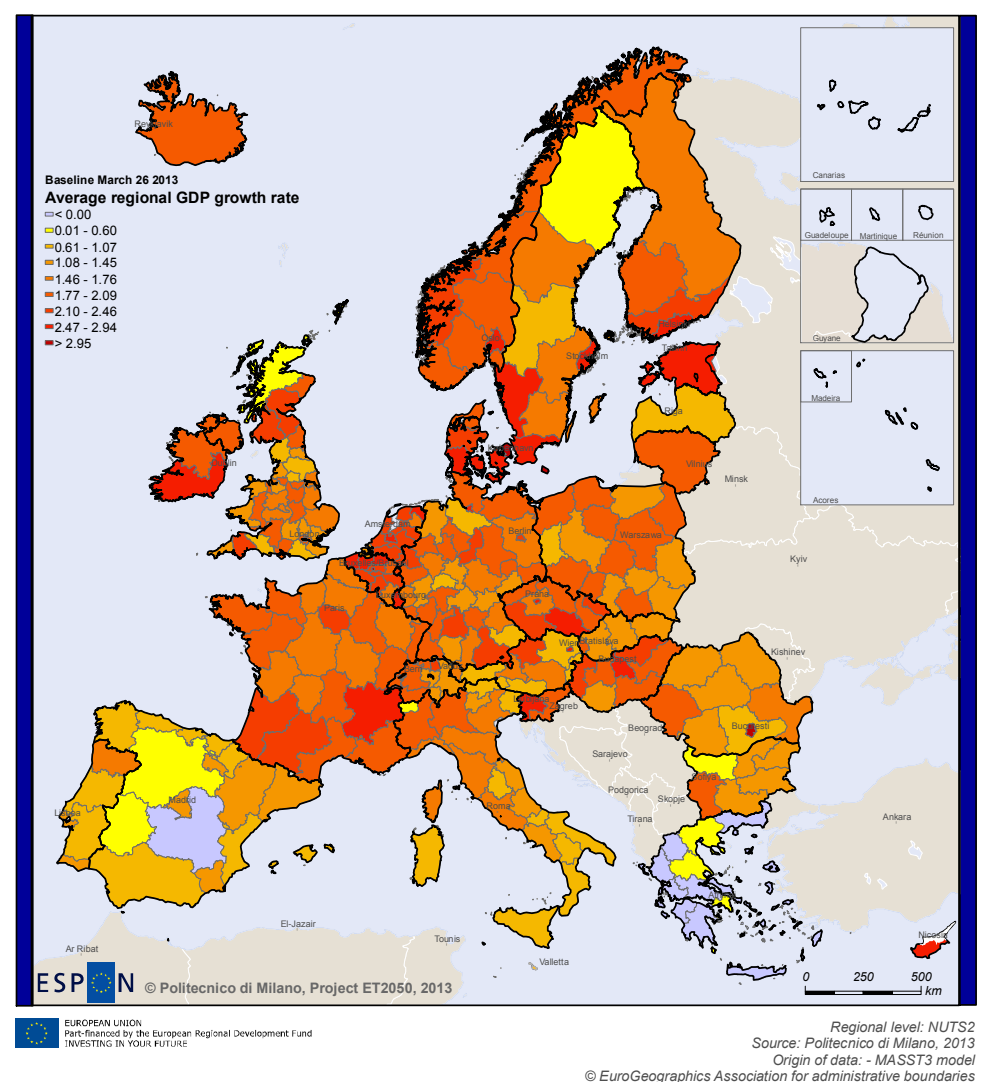

Source: Authors' elaboration

Fig 1. Average annual regional GDP growth rate forecasted by the MASST3 model, baseline scenario, 2012-2030

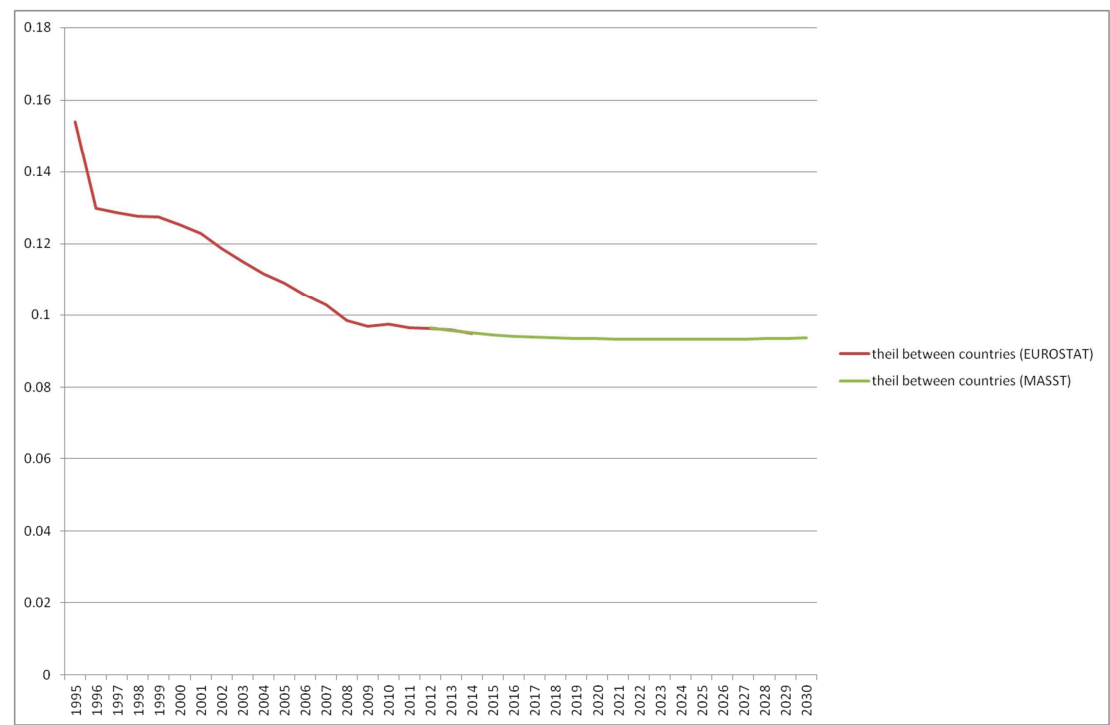

Source: own elaborations (Eurostat and ET2050 Espon Project)

Fig. 2 - Convergence interrupted: past and expected inter-national disparities in the EU Theil index 1995-2030

Centralized, top-down development strategies, overlooking regional specificities, explicitly renounce to support and exploit the strategic capabilities of intermediate institutional bodies, both public and private, that are present in a dispersed way in all territories - repeating in a different 
context the limits of centralized planning habits stigmatized by Friedrich von Hayeck (1978). These decentralized bodies are the best fit for interpreting the potential assets present in each territory and for generating, through a bottom-up 'discovery' process, the agreement on necessarily differentiated and 'place-based' development strategies (provided that the right incentives, rules and control systems are delivered from the centre) [20].

New research achievements in the area of innovation policies prove that even in the case of policies traditionally considered as 'excellence' ones, like R\&D and innovation policies, investing only in core, already competitive regions may not be the best strategy for maximizing aggregate growth. If it is true that R\&D support should be very selectively directed towards science-based regions, it looks also crucial that other innovation strategies could be devised and supported in regions operating inside other 'innovation 'patterns', e.g. enhancing inter-regional cooperation in knowledge applications or mobility of researchers, or favoring utilization of more advanced technologies in traditional specializations [21] [22] [23]. In this way, both growth and cohesion goals might be achieved.

Another recent research result bringing support to the thesis that an appropriate and smart design of regional policies could overcome the dilemma between competitiveness and cohesion comes from the already mentioned ESPON project, concerning the construction and assessment of territorial scenarios for the EU. Beyond a baseline scenario, three "exploratory" scenarios were built, namely:

1. a "Megas" scenario, a typical market driven scenario implying a concentration of investments in European large cities;

2. a "Cities" scenario, in which public policies are mostly at national level with a concentration of investments on second rank cities;

3. a "Regions" scenario, in which public resources are mostly devoted to social and development policies in lagging, rural and peripheral regions, presence of a strong public welfare system and a budget which is significantly increased for cohesion policies.

The first and the third scenarios can easily be interpreted respectively as a competitiveness and a cohesive scenario. The "cities" scenario, instead, embraces the philosophy of supporting second rank city regions, highly diffused in Europe and representing potentially productive areas, rich of specific, not fully exploited territorial capital assets and un-exploited agglomeration economies: it may be seen as an intermediate scenario, looking at the same time to enlarge the development area in relatively advanced regions and to pick the relatively better structured areas, namely urban areas, in lagging regions.

The results of the three scenarios - obtained by running a third version of the macroeconometric regional growth model MASST - are rather impressive. In aggregate terms, the "Cities scenario" is, at the same time the most expansionary among the three, both in Western and Eastern EU countries and also the most cohesive one, showing the least increase in overall regional disparities. As expected, the "Megas" scenario is the less cohesive, due to a very high increase in the withincountry disparities; on its turn, the "Regions" scenario is - almost by definition - the most cohesive in the within-countries disparities.

Trying to widen development outside the traditional core areas in the direction of second and third-rank European cities is likely to bring multiple advantages: exploiting a wider mass of potential territorial capital assets, avoiding the drawbacks of agglomeration diseconomies and the inflationary costs of excessive spatial concentration and supporting spill-over effects towards the urban poles of lagging and peripheral regions. 


\section{Regional development policies: acting through "territorial platforms".}

Territories may be conceived as multi-dimensional spaces: each dimension represents the presence of stocks of single typologies of territorial capital: location, size, quality, internal and external interactions. Relationships of functional, hierarchical of co-operative nature may take place inside the single dimension (economic, social, environmental, cognitive, identitarian, ...) or, more interestingly, among the different dimensions, generating huge and diversified cross-externalities and synergy effects.

The conceptual breakthrough allowed by the relatively new concept of territorial capital [5] [15] [24] consists in the almost infinite widening of the structural and functional relationships that are assumed to determine the growth potential of the single places / regions, along the scientific trajectory of the last seventy years, in the direction of an ideal place-based production function with heterogeneous capital assets. At the beginning, this trajectory was epitomized by Solow's simplified and stylized model with only two explicit arguments, namely capital and labor, and a third black box encompassing a large residual called 'technical progress'. During the 1970's, Solow's production function was enriched by the consideration of infrastructure and energy inputs and later on of different labour typologies, elements of social capital, information and knowledge. In this pathway, the 'quasi-production function' loses the possibility of interpreting distributive shares, but maintains the logical link with single, total and cross- factor productivity, ideally reducing the width of the residual unexplained element in regional development.

The full spectrum of territorial capital typologies may be considered and included, provided that good measures or proxies are available, ranging from material natural and cultural heritage to immaterial human and cognitive capital, from artificial public goods to private capital goods, from the structure of the urban system to identitarian capital, from club goods - like private networks - or impure public goods - subject to congestion effects and opportunistic behavior - to social or relational capital.

Regional policy interventions following a place-based philosophy should first of all recognize the multi-dimensional nature of development processes and the multi-layered nature of the territorial realm. This means:

- recognizing the necessity of an integrated and intersectoral approach to policy delivery, as perfectly demonstrated by the huge, pervasive and unexpected success of one of the bestdesigned European programmes, namely the Urban Initiative;

- tailoring each policy tool on the structural and territorial specificities of each place, interpreting its 'stage of development', its socio-economic structure, its knowledge endowment and learning capability, its typical 'innovation pattern' (as seen before);

- forcing actions addressed to achieving specific goals to interact synergetically with other policy goals: accessibility with environmental equilibrium; exploitation of natural and cultural heritage with the requirements of the identitarian evolution of places; knowledge creation with local production 'vocations' and entrepreneurial enhancement;

- addressing the conservation, completion, improvement and best use of the various typologies of territorial capital, selecting the excellence and most promising ones and combining those which look crucial for pursuing the most appropriate development strategy, devised from-below [8].

This integrated strategy can be synthesized by the concept of 'territorial platforms', a concept depicting a "territorialisation" philosophy of close matching and full integration - in functional, physical, economic, social and aesthetic terms - between new development projects and the local 
realm, at the same time mobilizing multiple local resources on a wide area in synergy with public action [25]. Four kinds of territorial platforms may be conceived:

- 'knowledge platforms', enlarging the scope of R\&D and innovation policies beyond the geographical limits of development poles, involving competences, human capital and mobility/education services on a wider geographical space (corridors, valleys, metropolitan areas, networks of cooperating cities);

- 'identity platforms', integrating conservation and wise exploitation of natural, cultural and landscape resources with complementary activities not only of tourism receptivity but also of research (environment and culture), education and training, advanced services provision (wellness and health services for new retired residents);

- 'infrastructure platforms', allowing the best integration of new infrastructure into the local environment, landscape and physical networks, considering feed-back effects of the provided new accessibilities on locational decisions of companies and real estate developments;

- 'urban platforms', enlarging development potential from single cities to city networks metropolitan urban systems, second-rank cities interlinked and co-operating on 'synergy' or 'complementarity urban networks' [6], city-regions organised on nodes, corridors and green networks - mainly operating on transport, communication and information infrastructure.

\section{References}

[1] F. Barca: An agenda for a reformed cohesion policy. Report to Commissioner for Regional Policy, Brussels, April (2009)

[2] Ph. McCann, R. Ortega Argilés: The role of the Smart Specialization Agenda in a reformed EU cohesion policy. In: Scienze Regionali - Italian Journal of Regional Science, Special Issue on "Smart specialization and the new EU cohesion policy reform", vol. 13, n. 1, (2014), pp.15-32

[3] R. Capello: Regional Economics, Routledge, New York (2007)

[4] R. Camagni: On the concept of territorial competitiveness: sound or misleading?. In: Urban Studies, n. 13, (2002), pp. 2395-2412

[5] OECD (2001), OECD Territorial Outlook, Paris

[6] R. Camagni: Policies for spatial development. In: OECD Territorial Outlook, Ch. 6, Paris, (2001), pp. 147-169

[7] R. Camagni: Technological change, uncertainty and innovation networks: towards a dynamic theory of economic space, in R. Camagni (ed.): Innovation networks: spatial perspectives, Belhaven-Pinter, London, (1991), pp. 121-144

[8] R. Camagni, D. Maillat (eds.): Milieux Innovateurs: théorie et politiques, Paris, Economica (2006)

[9] H. Armstrong., J. Taylor: Regional economics and policy, Blackwell, Oxford (2000)

[10] World Bank (2009), World Development Report, Washington

[11] R. Capello, R. Camagni, B. Chizzolini, U. Fratesi: Modelling regional scenarios for the enlarged Europe, Springer, Berlin (2009)

[12] R. Capello, U. Fratesi, L. Resmini: Globalization and regional growth in Europe, Springer, Heidelberg (2011)

[13] R. Capello, A. Caragliu, U. Fratesi: Forecasting Regional Growth between Competitiveness and Austerity Measures: the MASST3 Model, paper presented at the 53rd ERSA Conference, held in Palermo, Italy, 27-31 August (2013) 
[14] Sapir A. (2003), An agenda for a growing Europe, The Sapir Report to the EU, Brussels, July

[15] European Commission (2005), Territorial State and Perspectives of the European Union, Scoping Document and Summary of Political Messages, Brussels, May

[16] European Commission (2008), Turning territorial diversity intro strength - Green Paper on territorial cohesion, Communication from the Commission, Brussels, October

[19] European Commission (2009), Sixth Progress Report on economic and social cohesion, Report to the Parliament and the Council, Brussels

[20] M. Coffano, D. Foray: The centralità of entrepreneurial discovery in building and implementing a Smart Specialization Strategy. In: Scienze Regionali - Italian Journal of Regional Science, Special Issue on "Smart specialization and the new EU cohesion policy reform", vol. 13, n. 1, (2014), pp. 33-50

[21] R. Capello, C. Lenzi (eds.): Territorial patterns of innovation: an inquiry on the knowledge economy in European regions, Routledge, London (2013)

[22] R. Camagni, R. Capello: Towards a conclusion: smart innovation policies, in R. Capello, C. Lenzi (eds.), (2013), pp. 301-26

[23] R. Camagni, R. Capello, C. Lenzi: A territorial taxonomy of innovative regions and the European regional policy reform: smart innovation policies. In: Scienze Regionali - Italian Journal of Regional Science, Special Issue on "Smart specialization and the new EU cohesion policy reform", vol. 13, n. 1, (2014), pp. 60-106

[24] R. Camagni: Territorial capital and regional development. In: R. Capello, P. Nijkamp (eds.): Handbook of regional growth and development theories, Edward Elgar, Cheltenham (2009)

[25] R. Camagni: Policy options for the Latin Arc. In: R. Camagni, R. Capello (eds.): Spatial scenarios in a global perspective: Europe and the Latin Arc Countries, Edward Elgar, Cheltenham, (2011), pp. 175-185

[26] F. A. von Hayek: Competition as a Discovery Procedure. In: F. Hayek: New Studies in Philosophy, Politics, Economics and the History of Ideas, University of Chicago Press, (1978), pp. 179-190 